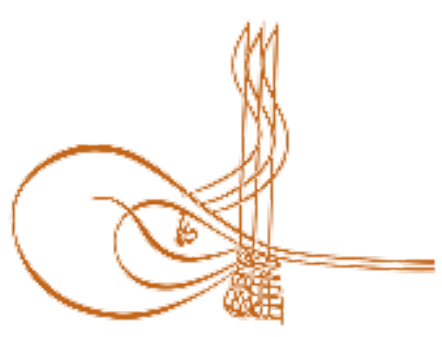

www.turkishstudies.net/education
Turkish Studies - Educational Sciences

eISSN: 2667-5609

Research Article / Araștırma Makalesi

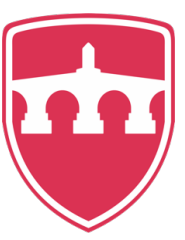

INTERNATIONAL BALKAN

UNIVERSITY

Sponsored by IBU

\title{
Sosyal Girişimcilik Öncülleri Ölçeğinin Türkçeye Uyarlanması: Geçerlik ve Güvenirlik Çalışması
}

\author{
Turkish Adaptation of the Social Entrepreneurial Antecedents Scale (SEAS): Validity and \\ Reliability Studies
}

\author{
Hüseyin Akar ${ }^{*}$
}

\begin{abstract}
The aim of the study is to adapt the social entrepreneurial antecedents scale, developed by Hockerts (2015) into Turkish. The study was conducted with four different study groups, composed of university students. The data of the study were collected between September 20 and December 15, 2019.The first study group consisting 30 students was tested on language equivalence. It was concluded that the form in English, the original language of the scale and the form in Turkish were equivalent $(r=.83 ; p<.05)$. The pilot scheme of Turkish form was conducted with the second study group consisting 60 students, and the total correlation values of each item and Cronbach Alpha values were analyzed. It was decided in this phase that the fourth item be removed from the scale. It was observed that remaining items were compatible with each other and the scale in general. In order to test the validity of the scale having 17 items and 4 dimensions in its current shape, CFA was conducted with the third study group, consisting 305 students. CFA results revealed that the scale had model compatibility $\left(\chi^{2} / \mathrm{sd}=248.29 / 111=2.34 ; \mathrm{p}<.05, \mathrm{CFI}=.92 ; \mathrm{TLI}=.91 ; \mathrm{GFI}=.91\right.$; SRMR $=.076$; RMSEA $=.064)$. However, it was also concluded that factor loading of items composing the scale varied between .33 and .88 . Test-retest analysis and internal consistency coefficient were used for the analysis of the reliability of the scale. Cronbach Alpha and test-retest coefficients regarding sub-dimensions of the scale are as follows: empathy $(.70 ; .80)$, moral obligation $(.83 ; .79)$, self-efficacy $(.72 ; .71)$ and social support $(.81 ; .88)$. According to validity and reliability analyses, it can be noted that Turkish form of the scale is valid and reliable.
\end{abstract}

Structured Abstract: Introduction Today's world is faced with more problems than ever seen in its history. It has become ordinary to see news about global problems such as global warming, climate change, environmental pollution, natural disasters, illnesses, lack of education, poorness, offense, violence against woman, child abuse, economic crises, drought and migration in the media almost every day. Regarding these problems, a common voice is raised by the whole society regarding what should be done and what kind of a route should be followed in overcoming problems. It is seen that the most suitable and promising notion of

\footnotetext{
* Dr. Öğr.Üyesi, Kilis 7 Aralık Üniversitesi, Muallim Rıfat Eğitim Fakültesi, Eğitim Bilimleri Bölümü Asst. Prof. Dr., Kilis 7 Aralik University, Muallim Rufat Faculty of Education, Department of Educational Sciences **Bu çalışmanın verileri 20 Eylül-15 Aralık 2019 tarihleri arasında toplanmıştır. ORCID 0000-0002-0453-6465

huseyinakar@kilis.edu.tr

Cite as/ Atıf: Akar, H. (2020). Sosyal girişimcilik öncülleri ölçeğinin türkçeye uyarlanması: geçerlik ve güvenirlik çalışması, Turkish Studies - Education, 15(2), 579-593. https://dx.doi.org/10.29228/TurkishStudies.40562

Received/Geliş: 14 January/Ocak 2020

Checked by plagiarism software

Accepted/Kabul: 25 April/Nisan 2020

Published/Yayın: 30 April/Nisan 2020

Copyright (C INTAC LTD, Turkey

CC BY-NC 4.0
} 
this voice is social entrepreneurship. In this context, social entrepreneurship may be the best healer for society as the first and most important response to unmet individual and social needs and problems (Haugh, 2007). In a world where there are political authorities facing many problems and cannot find effective solutions most of the time, social entrepreneurship has an important impact on finding solutions for social problems (Sassmannshausen and Volkmann 2013). Social entrepreneurship, having socialness and entrepreneurship at its core, includes dealing with social problems using an entrepreneurial point of view in its simplest form (Kümbül Güler, 2008). In this regard, social entrepreneurship is defined as entrepreneurial activities aimed at society (Austin Stevenson and Wei-Skillern 2006). Social entrepreneurs focus on innovative and entrepreneurial approaches in determining social problems and offering solutions in the short and the long term and put forth innovative business models in order to solve problems and meet complex social needs (Miller, Grimes, McMullen and Vogus, 2012; Borzaga and Depedri, 2013). Studies demonstrate that activities on social entrepreneurship increase economic growth as well as improving the life quality of society, decreasing poverty and providing social change considerably (Austin et al., 2006; Henton, Melville and Walesh, 1997; Zahra, Gedajlovic, Neubaum and Shulman, 2009). It is remarkable that social entrepreneurship has attracted a considerable interest in national and international literature over the recent years. It is observed in most of these studies that the main focal point is social entrepreneurial intention. Since the intention is the basis of behavior, determining factors on social entrepreneurial intention is deemed of utmost importance. In this regard, one of the most important and valid models in the literature is the 4component model, developed by Mair and Noboa (2006). According to this model, social entrepreneurial intention is composed of 4 basic components. These are empathy, social moral obligation, social entrepreneurial self-sufficiency, and perceived social support. Hockerts (2015) developed the social entrepreneurial antecedents scale based on the 4-component model of Mair and Noboa (2006) on social entrepreneurial intention. It is underlined that this scale may guide the authorities in terms of determining the efficiency of training and taking measures in order to correct the deficiencies in social entrepreneurship training. Moreover, social entrepreneurial intention of individuals and their social entrepreneurial features can be analyzed using this scale. Therefore, this scale may lead the process where training programs for social entrepreneur candidates are formed. When the above-mentioned benefits of the social entrepreneurial antecedents scale developed by Hockerts (2015) are considered, it is thought that the scale will also contribute to the national literature. It is expected that this scale will play a significant role especially on the process in which social entrepreneur individuals are trained.

\section{Method}

Social entrepreneurial antecedents scale, developed by Hockerts (2015), is comprised of 18 items and 4 factors. The factors of the scale are as follows: empathy, social moral obligation, social entrepreneurial self-sufficiency, and perceived social support. Items 2, 4, 6, 14, and 18 on the scale have reverse scoring. The scale has 5 -point Likert-type scoring ( $1=$ Strongly disagree... $5=$ Strongly agree). In the reliability analysis conducted by Hockerts (2015), Cronbach Alpha values of empathy, social moral obligation, social entrepreneurial self-sufficiency, and social support dimensions of the scale were calculated as $.865, .828$, .821 and .797 respectively.

The study was conducted with 4 different study groups consisting of university students. The first study group is composed of 30 students studying in the Faculty of Education, Department of English Teaching of Inonu University. Data obtained from this study group was used in testing the language validity. The second study group consisted of 60 students studying in different departments of Muallim Rifat Faculty of Education of Kilis 7 Aralik University. The third study group consisted of 305 students studying in different faculties and departments in Kilis 7 Aralik University, who volunteered to take part in the study. Data obtained from this study group was used in the CFA (confirmatory factor analysis) conducted in order to confirm the current shape of the scale. The fourth study group consisted of 95 students studying in Muallim Rifat Faculty of Education of Kilis 7 Aralik University. Data obtained from this study group was used in test-retest reliability analysis. SPSS and AMOS programs were used for the analyses. The significance level was .05 .

\section{Results}

It was concluded in the language equivalence test that the form in English, the original scale, and the form in Turkish were equivalent $(\mathrm{r}=.83 ; \mathrm{p}<.05)$. The fourth item of the scale was removed from the Turkish form in the pilot scheme because its total correlation coefficient was below .20. It was observed that total 
correlation coefficient of remaining items varied between .26 and .57. The Cronbach Alpha coefficient of the overall scale was calculated as .83 . In order to test the validity of the scale having 17 items and 4 dimensions in its current shape, CFA was conducted with the third study group, consisting 305 students. CFA results revealed that the scale had model compatibility $\left(\chi^{2} / \mathrm{sd}=248.29 / 111=2.34 ; \mathrm{p}<.05, \mathrm{CFI}=.92 ; \mathrm{TLI}=.91\right.$; GFI $=.91 ;$ SRMR $=.076 ;$ RMSEA $=.064)$. However, it was also concluded that factor loading of items composing the scale varied between .33 and .88 . Test-retest analysis and internal consistency coefficient were used for the analysis of the reliability of the scale. Cronbach Alpha and test-retest coefficients regarding sub-dimensions of the scale are as follows: empathy $(.70 ; .80)$, moral obligation $(.83 ; .79)$, self-efficacy $(.72$; $.71)$ and social support $(.81 ; .88)$.

\section{Conclusion}

The aim of the study is to adapt the social entrepreneurial antecedents scale, developed by Hockerts (2015) and based on the model developed by Mair and Noboa (2006) explaining the formation of social entrepreneurial intention into Turkish. The validity and reliability analyses were conducted within the context of adapting the scale consisted of 18 items and 4 factors, into Turkish. First, the scale was translated into Turkish, complying with the principles stated in the literature (Brislin, Lonner and Thorndike, 1973; Savaşır, 1994). Whether the form in English and the form in Turkish regarding the scale was equivalent was tested. Then, the pilot study was conducted on the Turkish form of the scale, and Cronbach Alpha coefficient of the overall scale and total correlation values of each item on the scale were calculated. CFA was performed in order to test the validity of the scale having 17 items and 4 dimensions in its current shape. After the validity analyses, the reliability of the scale was tested. Cronbach Alpha internal consistency and test-retest analysis results were used in testing the reliability. According to validity and reliability analyses, it can be noted that Turkish form of the scale is valid and reliable.

Keywords: Educational Administration, Social Entrepreneurship, Scale, Turkish Adaptation, Validity, Reliability

Öz: Bu çalışmanın amacı, Hockerts (2015) tarafından geliştirilmiş olan, sosyal girişimcilik öncülleri ölçeğini Türkçeye uyarlamaktır. Çalışma, üniversite öğrencilerinden oluşan birbirinden farklı 4 çalışma grubuyla gerçekleştirilmiştir. Çalışmanının verileri 20 Eylül-15 Aralık 2019 tarihleri arasında toplanmıştır. 30 öğrenciden oluşan birinci çalışma grubuyla dil eşdeğerliği test edilmiştir ve ölçeğin orijinal dili olan İngilizce formu ile Türkçe formunun birbirine eş değer olduğu sonucuna ulaşılmıştır $(r=.83 ; \mathrm{p}<.05)$. Altmış öğrenciden oluşan ikinci çalışma grubuyla ölçeğin Türkçe formunun pilot uygulaması gerçekleştirilmiş ve her bir maddeye ait madde toplam korelasyon değerleri ile Cronbach Alfa değerleri incelenmiştir. Bu aşamada orjinal ölçekte yer alan bir maddenin ölçekten çıkarılmasına karar verilmiştir. Geriye kalan maddelerin birbirleriyle ve ölçeğin geneli ile uyumlu olduğu görülmüştür. 305 öğrenciden oluşan üçüncü çalışma grubuyla 17 madde ve 4 boyuttan oluşan ölçeğin mevcut yapısının geçerliği test etmek amaciyla DFA yapılmış ve DFA sonucunda ölçeğin model uyumuna sahip olduğu görülmüştür $\left(\chi^{2} / \mathrm{sd}=248.29 / 111=\right.$ 2.34; $\mathrm{p}<.05, \mathrm{CFI}=.92 ; \mathrm{TLI}=.91 ; \mathrm{GFI}=.91 ; \mathrm{SRMR}=.076 ; \mathrm{RMSEA}=.064)$. Bununla birlikte ölçeği oluşturan maddelerin faktör yüklerinin .33 ile .88 arasında değiştiği sonucuna ulaşılmıştır. Ölçeğin güvenirliği incelenmesinde test-tekrar test analizi ve iç tutarlık katsayısı kullanılmıştır. Ölçeğin alt boyutlarına ilişkin Cronbach Alfa ve test-tekrar test değerleri sırayla şu şekildedir; empati $(.70 ; .80)$, ahlaki yükümlülük $(.83 ; .79)$, öz yeterlik $(.72 ; .71)$ ve sosyal destek $(.81 ; .88)$. Yapılan geçerlik ve güvenirlik analizlerine göre ölçeğin Türkçe formunun geçerli ve güvenilir olduğu ifade edilebilir.

Anahtar Kelimeler: Eğitim Yönetimi, Sosyal Girişimcilik, Ölçek, Türkçe Uyarlama, Geçerlik, Güvenirlik

\section{Giriş}

Günümüz dünyası, tarihinde hiç olmadığı kadar çok problemle karşı karşıya bulunmaktadır. Medyada hemen hemen her gün, küresel ısınma, iklim değişikliği, çevre kirliliği, doğal afetler, hastalıklar, eğitimsizlik, yoksulluk, suç, kadına şiddet, çocuk istismarı, ekonomik krizler, kuraklık, savaş ve göç gibi küresel sorunlarla ilgili haberler görmek sıradan bir hale gelmiştir. $\mathrm{Bu}$ sorunlar karşında, tüm toplumdan sorunların üstesinden gelmede ne yapılması ve nasıl bir yol izlenmesi gerektiği ile ilgili ortak bir ses yükselmektedir. Bu sese en uygun ve yerinde 
karş1lk veren olgunun ise sosyal girişimcilik olduğu görülmektedir. Bu bağlamda sosyal girişimcilik, karşılanmamış bireysel ve toplumsal ihtiyaçlara ve sorunlara ilk ve en önemli tepki olarak, toplumun en iyi sorun çözücüsü olabilir (Haugh, 2007). Birçok sorunla yüzleşen ve çoğu zaman bu sorunlara etkili çözüm bulamayan siyasi otoritelerin olduğu bir dünyada sosyal girişimcilik, sosyal problemleri çözmede önemli etkiye sahiptir (Sassmannshausen ve Volkmann 2013). Sosyal girişimciliğin sosyal ekonomik ve çevresel alanlarda değer üretmede etkili bir mekanizma olduğu yaygın olarak kabul edilmektedir (Anheier ve Themudo, 2002).

Sosyal girişimcilik kavramı nispeten yeni bir kavram gibi görünse de tarihin her döneminde sosyal girişimcilik faaliyetlerinde bulunan insanlar ve kurumlar sürekli var olmuştur. Kavramsal olarak incelendiğinde, sosyal girişimcilik kavramının ilk kez 1972'de sosyal değişim alanında yapılan araştırmalarda kullanıldığı görülmektedir. Ancak kavramın yaygın kullanımı 1990'lar da gerçekleşmiştir. 1981'de sosyal girişimciliği teşvik etmek amaciyla çalışan bir örgüt olan Ashoka'nın ve 1998'de Schwab Vakfının kuruluşu kavramın yaygınlaşmasına katkı sağlamıştır. Ayrıca sosyal girişimciliği teşvik etmek amacıyla insanlara mikro kredi sağlayan ve Muhammed Yunus öncülüğünde kurulmuş olan Grameen Bank'ın çalışmalarından dolayı 2006'da Muhammed Yunus'un Nobel Barış ödülüne layık görülmesi sosyal girişimciliğin gelişmesinde önemli bir rol oynamıştır (Snellman, 2016). Özünde sosyalliği ve girişimcilik olgusunu barındıran sosyal girişimcilik, en basit şekliyle toplumsal sorunları girişimci bakış açısıyla ele almayı içermektedir (Kümbül Güler, 2008). Bu yönüyle sosyal girişimcilik sosyal amaçlı girişimci faaliyetler olarak tanımlanmaktadır (Austin Stevenson ve Wei-Skillern 2006). Sosyal girişimcilik esas itibari ile sosyal değer yaratmayı amaçladığı için her sosyal girişimci faaliyetin içinde mutlaka bir sosyal amacın olması gerekmektedir. Kişisel düzeyde yapılan sosyal girişimcilik tanımları incelendiğinde; sosyal girişimciler sosyal amaçları olan, sosyal adaleti sağlama arzusuyla hareket eden, sosyal dönüşüm için gerekli fikirleri, yetenekleri, kaynakları ve düzenlemeleri harekete geçiren ve sosyal problemlere yenilikçi çözümler üreten değişim ajanları olarak tanımlanmaktadır (Alvord, Brown ve Letts, 2004; Dees, 1998; Thake ve Zadek, 1997). Sosyal girişimciler, toplumsal sorunların belirlenmesi, kısa ve uzun vadede çözüm önerilerinin ortaya konulmasında yenilikçi ve girişimci yaklaşımlara odaklanmakta, sorunları çözmek ve karmaşık sosyal ihtiyaçları karşılamak için yenilikçi iş modelleri ortaya koymaktadır (Borzaga ve Depedri, 2013; Miller, Grimes, McMullen ve Vogus, 2012). Dolaysıyla sosyal girişimciler içinde yaşadıkları çevrede ve toplumda bir problem gördüklerinde bu problemi çözmeye yönelik eyleme geçme eğiliminde olan kişilerdir. Sosyal girişimcilerin esas amacı para kazanmak veya kar elde etmek değildir. Aksine toplumun sorunlarını çözmek, ihtiyaçlarını ve isteklerini karşılamak (Dees, 1998; Drayton, 2002; Sivathanu ve Behise, 2013) ve dünyayı daha yaşanılabilir bir yer haline getirmektir (Akar ve Doğan, 2018).

Sosyal girişimcilerin amacı sosyal problemlere kalıcı çözümler bulmak ve sosyal değer yaratmak olduğu halde kendi misyonlarını devam ettirebilmek için aynı zamanda finansal kâr üretmeleri de gerekmektedir. Sosyal girişimci için ekonomik değer nihai amacı temsil etmez ancak yeniliğin, girişimlerin ve finansmanın sürdürebilirliğini sağlamak için önemli bir yan etkiyi temsil ettiğinden dolayı ciddi bir şekilde ele alınması gerekmektedir (Mair ve Marti 2006).

Yapılan araştırmalar sosyal girişimcilikle ilgili faaliyetlerin ekonomik büyümeyi arttırdığı, toplumun yaşam kalitesini geliştirdiği, yoksulluğu azalttı̆̆ gerçekleştirdiği göstermektedir (Austin ve diğ., 2006; Henton, Melville ve Walesh, 1997; Zahra, Gedajlovic, Neubaum ve Shulman 2009). Özellikle yoksul ve kenara itilmiş/dışlanmış toplumların/grupların sorunlarına odaklanan uygulamalardan bazıları, dünyadaki binlerce insanın hayatını değiştirmeyi başarmıştır (Alvord, Brown ve Letts, 2004).

Sosyal girişimcilerin özellikleri incelendiğinde, kendi kendini güdüleyebilme, kararlılık, liderlik, risk alabilme, vizyonu iletebilme, diğerlerine ilham verebilme, kaynakları en üst düzeyde kullanabilme, yüksek düzeyde empati ve öz yeterlik gibi niteliklere ve dişa dönüklük, deneyime 
açıklık gibi kişilik özelliklerine sahip oldukları görülmektedir (Akar ve Aydın, 2015; Akar ve Üstüner, 2017; Pearce, 2003; Shaw ve Carter, 2007).

Son yıllarda ulusal ve uluslararası alan yazında sosyal girişimciliğe yönelik yoğun bir ilginin olduğu dikkat çekmektedir (Akar ve Doğan, 2018; Akar ve Üstüner, 2017; Aydoğmuş, 2019; Chinchilla ve Garcia, 2017; Dees, 2012; Drayton, 2002; Forster ve Grichnik, 2013; Hockerts, 2015; Hockerts, 2010; Hockerts, 2017; Ip, Wu, Liu ve Liang, 2017; Konakl1, 2015; Konaklı ve Göğüş, 2013; Mair ve Noboa, 2006; Sezen-Gültekin ve Gür-Erdoğan, 2016; Yazıcı, Uslu ve Arık, 2016; Tiwari, Bhat ve Tikoria, 2017). Bu çalışmaların önemli bir kısmında, odaklanılan temel konunun sosyal girişimcilik niyeti olduğu görülmektedir. Davranışların temelinde niyet olduğu için sosyal girişimciliğe niyetini oluşturan etmenleri belirlemek önemli kabul edilmektedir. Bu konuda alan yazında geçerliği kabul edilen en önemli modellerden biri de Mair ve Noboa'nın (2006) öne sürdüğü 4 bileşenli modeldir. $\mathrm{Bu}$ modele göre sosyal girişimcilik niyeti 4 temel bileşenden oluşmaktadır. Bunlar; empati, toplumsal ahlaki yükümlülük, sosyal girişimcilik öz yeterliği ve algilanan sosyal destektir.

Empati. Empati alan yazında yaygın olarak diğer insanların yaşadığı duyguların, bilişsel olarak farkına varma ve duygusal olarak onları paylaşma olarak tanımlanan bir kavramdır (Decety ve Jackson 2004). Empatinin temelinde kişinin kendini karşındakinin yerine koyabilmesi, onun duygu ve düşüncelerini anlayabilmesi yatmaktadır (Dökmen, 2013). Bu bağlamda ihtiyacı olan insanlara yardım etmede, empatinin önemli bir etkiye sahip olduğu vurgulanmaktadır (McDonald ve Messinger, 2010). Diğer bir ifadeyle başkalarının duygularına yönelik hassasiyete sahip olmak sosyal girişimcileri sosyal girişimlerde bulunmaya teşvik etmektedir (Praphu, 1999). Bu bağlamda, Eisenberg ve Miller (1987) başkaları adına eylemde bulunmada empatinin gerekli bir koşul olduğunu belirtmektedir. Mair ve Noboa (2006) da bu görüşü desteklemektedir. Sosyal teşebbüsler için belirli düzeyde empatinin olması gerektiğini ifade etmektedir. Bu açıdan empati sosyal girişimciliğin önemli bir bileşeni olarak kabul edilmektedir (Mair ve Noboa, 2006). Yapılan çalışmalarda da empatinin sosyal girişimcilik niyeti ile pozitif yönde ilişkili olduğu belirtilmektedir (Ayob, Yap, Sapuan ve Rashidd, 2013; Forster ve Grichnik, 2013; Hockerts, 2017; Ip ve diğ., 2017; Teise ve Urban, 2015).

Toplumsal ahlaki yükümlülük. Ahlaki yükümlük kişinin, belirli bir durumda temel sosyal haklarından mahrum insanlara yardım etme sorumluluğunu hissetme derecesini anlatan bir kavramdır (Tiwari ve diğ., 2017). Hockerts (2015) göre ahlaki yükümlük, algılanan ahlaki normların ve değerlerin bir sonucu olarak bireyin, toplumun dışına itilmiş/dışlanmış insanların/grupların problemlerini çözmek zorunda olduğunu hissetme derecesi ile ilgilidir. Birçok çalışmada ahlaki standartlara bağl1lığın sosyal girişimcilerin en önemli özelliği olduğu vurgulanmaktadır (Akar ve Doğan, 2017; Ip, Liang, Wu, Law ve Liu, 2018). Sosyal girişimciler ahlaki sorunlarla karşılaştıklarında sosyal normlara ve değerlere uygun davranma yükümlülüğü hissetmektedirler (Beck ve Ajzen, 1991). Bu açıdan sosyal girişimcilerin yüksek bir ahlaki yapıya sahip oldukları ve bu özelliklerinin de onları insanların ihtiyaçlarını karşılamaya yönelik motive ettiği ifade edilebilir (Bornstein, 1998; Nga ve Shamuganathan, 2010).

Sosyal girișimcilik öz yeterliği. Sosyal girişimcilik öz yeterliği, bireyin toplumsal sorunların çözümüne katkıda bulunabilecek yeni bir girişimi başarılı bir şekilde başlatabileceği ile ilgili inancını ifade eden bir kavramdır (Campo, 2010; Hockerts, 2015). Başka bir ifadeyle bireyin, sosyal bir girişimci olmak için gerekli olan rol ve görevleri yerine getirme becerisine olan inancıdır (Boyd ve Vozikis, 1994). Öz yeterlik algısının yüksek alması, bireylerin sosyal girişimlerde bulunmasını kolaylaştırmaktadır (Mair ve Noboa, 2006). Yapılan çalışmalarda öz yeterliğin sosyal girişimciliğin en önemli yordayıcılarından biri olduğu görülmektedir (Akar ve Üstüner, 2017; Fitzsimmons ve Douglas, 2011; Forster and Grichnik, 2013; Tyszka, Cieślik, Domurat ve Macko 2011). 
Algılanan sosyal destek. Sosyal girişimciler, sosyal bir girişimin gerçekleştirile bilirliğini belirlerken arkadaş ve aileleri başta olmak üzere diğer insanlardan alabilecekleri desteği göz önünde bulundururlar (Bornstein,1998; Hockerts, 2015). Başarılı girişimciler etkili sosyal ağlara sahiptir ve bu ağlar kişinin iletişim kurduğu herkesi kapsamaktadır. Girişimcilerin ihtiyaç duyduğu sosyal destek esas itibari ile sosyal sermayeye dayalıdır ve çoğunlukla dayanışma, güven ve sivil ruh kavramları ile ilişkilidir (Mair ve Noboa, 2006). Taylor ve Thorpe (2004) sosyal ağların girişimsel süreçte sosyal girişimcinin kararlarını etkileyen bir bilgi kaynağı olarak hareket edebileceğini belirtmektedir. Evans ve Jovanovic'e (1989) göre ise sosyal girişimciler aile üyelerinden, arkadaşlarından ya da diğer kişi ve kurumlardan gelecek bilgi ve tavsiyelerle etkili girişimlerde bulunabilirler.

Hockerts (2015), Mair ve Noboa'nın (2006) sosyal girişimcilik niyeti ile ilgili öne sürdüğü 4 bileşenli modele dayalı olarak sosyal girişimcilik öncülleri ölçeğini geliştirmiştir. Bu ölçeğin, özellikle sosyal girişimcilik eğitimlerinde, eğitimin etkililiğini belirlemede ve eğitimin eksiklikleri gidermeye yönelik önlemlerin alınmasında yetkililere yol gösterebileceği vurgulanmaktadır. Ayrıca bu ölçek aracılığıyla bireylerin sosyal girişimcilik niyetleri, sosyal girişimcilik eğilimleri ve sosyal girişimcilik özellikleri belirlenebilir. Böylece sosyal girişimci olmaya aday kişilerin eğitim programlarının oluşturulması sürecine rehberlik edebilir. Hockerts (2015) tarafından geliştirilmiş olan sosyal girişimcilik öncülleri ölçeğinin yukarıda ifade edilen faydaları düşünüldüğünde ölçeğin ulusal alan yazına katk1 sağlayabileceği düşünülmektedir. Özellikle sosyal girişimci bireylerin yetiştirilmesi sürecinde belirleyici rol oynaması beklenmektedir.

\section{Yöntem}

\section{Çalışma Grubu}

$\mathrm{Bu}$ çalışma, 2019-2020 öğretim yılında İnönü Üniversitesi ve Kilis 7 Aralık Üniversitesinde öğrenim gören öğrencilerden oluşan birbirinden farklı 4 çalışma grubuyla gerçekleştirilmiştir. Birinci çalışma grubunu İnönü Üniversitesi eğitim fakültesinde İngilizce öğretmenliği programında öğrenim gören 30 öğrenci oluşturmaktadır. Bu çalışma grubundan elde edilen veriler dil geçerliğini test etmede kullanılmıştır. İkinci çalışma grubu, Kilis 7 Aralık Üniversitesi-Muallim Rıfat Eğitim Fakültesinde farklı programlarda öğrenim gören 60 öğrenciden oluşmaktadır (öğrencilerin: \%45'i erkek, $\% 55$ kadındır; öğrencilerin yaş ortalaması 22 dir). Üçüncü çalışma grubunu, Kilis 7 Aralık Üniversitesinde farklı fakülte ve yüksek okullarda (Fen Edebiyat Fakültesi, Eğitim Fakültesi, İktisadi ve İdari Bilimler Fakültesi, İlahiyat Fakültesi ve Teknik Bilimler Yüksek Okulu) öğrenim gören ve araştırmaya katılmaya gönüllü olan 305 öğrenci oluşturmaktadır (öğrencilerin: \%48'i erkek, \%52'si kadındır; öğrencilerin yaş ortalaması 20,5'dir). $\mathrm{Bu}$ çalışma grubundan elde edilen verilerle ölçeğin mevcut yapısının doğrulamaya yönelik doğrulayıcı faktör analizi (DFA) yapılmıştır. Dördüncü çalışma grubu ise Kilis 7 Aralık Üniversitesi-Muallim Rifat Eğitim Fakültesinde öğrenim gören 95 öğrenciden oluşmaktadır (öğrencilerin: \%41'1 erkek, \%59'u kadındır; öğrencilerin yaş ortalaması 21,5'tir). Bu çalışma grubundan elde edilen veriler test-tekrar test güvenirlik analizi için kullanılmıştır.

\section{Sosyal Girişimcilik Öncülleri Ölçeği}

Sosyal girişimcilik öncülleri ölçeği; Hockerts (2015) tarafından, Mair ve Noboa'nın (2006) sosyal girişimcilik niyetinin en önemli yordayıcısı olarak ifade ettiği empati, toplumsal ahlaki yükümlülük, sosyal girişimcilik öz yeterlik algısı ve sosyal destek inancı değişkenlerinde oluşan modeli temele alınarak geliştirilmiştir. Hockerts (2015) ölçek geliştirme çalışmasında iki grupla çalışmıştır. Her iki grupta Kopenhag işletme okulunda eğitim gören öğrencilerden oluşmaktadır. Ölçeğin örtük yapısını belirlemek amacıyla yapılan açımlayıcı faktör analizi, işletme okulunda yönetim bilimlerinde yüksek lisans yapan 237 öğrenciden elde edilen verilerle gerçekleştirilmiştir. Açımlayıcı faktör analizi sonucunda 18 maddeden oluşan 4 boyutlu (empati, toplumsal ahlaki yükümlülük, sosyal girimcilik öz yeterliği, algılanan sosyal destek) bir yapı ortaya çıkmıştır. 
Açımlayıcı faktör analizi sonucunda oluşan yapının doğrulanması için gerçekleştirilen doğrulayıcı faktör analizinde ise işletme okulunda fen bilimleri lisans programına kayıtlı 192 öğrenciden elde edilen veriler kullanılmıştır. DFA sonucunda elde edilen uyum iyiliği değerleri incelendiğinde ölçeğin 18 maddeden oluşan 4 boyutlu mevcut yapısının doğrulandığı görülmektedir $\left(\left(\chi^{2} / \mathrm{sd}=1.47\right.\right.$; $\mathrm{p}<.05, \mathrm{CFI}=.97$; IFI $=.96 ;$ SRMR $=.05 ;$ RMSEA $=.03)$. Ölçeğin empati, toplumsal ahlaki yükümlülük, sosyal girimcilik öz yeterliği, sosyal destek boyutlarına ait Cronbach Alfa değerleri sırayla; $.865, .828, .821$ ve .797 olarak hesaplanmıștır. Ölçekte yer alan $2,4,6,14$ ve 18 maddeleri olumsuz yargı bildirdiğinden ters puanlanmaktadır. Ölçek 5'li likert tipi puanlamaya sahiptir $(1=$ Kesinlikle katılmıyorum...5= Kesinlikle katılıyorum). Kai Hockerts ile mail aracıllğıyla iletişime geçilmiş ve ölçeğin Türkçeye uyarlanması ile ilgili gerekli izinler alınmıştır.

\section{Verilerin Analizi}

Ölçeğin Türkçe ve İngilizce formu 2 hafta süreyle aynı gruba uygulanmış ve her iki formdan elde dilen verilerin ortalamaları arasındaki ilişki korelasyon analizi ile incelenmiştir. 60 kişilik öğrenci grubu ile ölçeğin Türkçe formunun pilot uygulaması gerçekleştirilmiştir. Her bir ölçek maddesine ilişkin madde toplam korelasyon katsayısı ve ölçeğin geneline ilişkin Cronbach Alfa değeri hesaplanmıştır. Ölçeğin 4 faktörlü yapısını doğrulamak amacıyla DFA yapılmıştır. 95 öğrenci ile ölçeğin uygulamadan uygulamaya tutarlı sonuçlar verip/vermediğini belirlemek amacıyla 3 hafta arayla test-tekrar test güvenirlik analizleri yapılmış ve iki uygulama arasındaki ilişki korelasyon analizi ile incelenmiştir. Analizlerin yapılmasında SPSS ve AMOS bilgisayar programların yararlanılmıştır. Anlamlılık düzeyi .05 olarak alınmıştır.

\section{Bulgular}

Sosyal girişimcilik öncülleri ölçeğinin Türkçeye uyarlanmasında alan yazında belirtilen basamaklar izlenmiştir (Seçer, 2015). Bu doğrultuda; ölçeğin çevirisi, dil eşdeğerliğinin incelenmesi, ölçeğin Türkçe formunun pilot uygulaması, ölçeğin mevcut yapısının geçerliği ve ölçeğin güvenirliği ile ilgili işlemler sırayla gerçekleştirilmiş̧ir.

\section{Çeviri Aşaması}

Ölçek uyarlama çalışmalarında en önemli aşamalardan biri çeviri aşamasıdır. Ölçeğin orijinal dilinden hedef dile çevrilmesinde uyulması gereken önemli bazı ilkeler vardır. Çeviri işlemini yapacak kişilerin her iki dili de iyi bilmeleri, ölçeğin konusu ile ilgili bilgi sahibi olmaları ve her iki kültürde deneyim sahibi olmaları gerekmektedir (Savaşır, 1994). Ölçeği çevirecek kişilerin belirlenmesinde mümkün olduğunca bu ilkelere uyulmaya çalışılmıştır. Ölçeğin orijinal dilinden (İngilizce) hedef dile (Türkçe) çevrilmesinde; çevirinin yapılması, çevirinin değerlendirilmesi, çeviriyi tekrar orijinal diline çevirme, geri çeviriyi inceleme ve uzman görüşünden oluşan 5 aşamalı sıra izlenmiştir (Brislin, Lonner ve Thorndike, 1973). Ölçeğin çevirisi İngilizce öğretmenliğinden mezun, İngilizceyi iyi bilen ve eğitim bilimleri bölümünde öğretim üyesi olan 2 kişi tarafından yapılmıştır. Bu süreçte öncelikle çevirmenler birbirinden bağımsız olarak ölçeği Türkçeye çevirmiştir. Daha sonra çevirmenler bir araya gelip her iki çeviriyi de incelemiş, farklılık gösteren ifadeler belirlenmiş ve her ikisinin de ortak görüşü ile bu ifadeler yeniden düzenlenmiştir. Türkçeye çevrilen ölçek 2 İngilizce okutmanı tarafından yeniden İngilizceye çevrilmiş ve bu çeviriler ölçeğin İngilizce formu ile karşılaştırılmıştır. Bu incelemeden sonra Türkçe eğitimi ana bilim dalın görevli bir öğretim üyesinin ve ilgili konuda uzman iki öğretim üyesinin görüşü alınarak ölçeğin son şekli (uygulama formu) oluşturulmuştur.

\section{Dilsel Geçerlik Çalışması}

Ölçeğin İngilizce formu ile Türkçe formunun eşdeğer olup/olmadığını belirmek amacıyla İnönü Üniversitesi-Eğitim Fakültesi-İngilizce öğretmenliği bölümünde öğrenim gören ve 30 kişiden oluşan gruba 2 hafta arayla uygulanmıştır. Daha sonra ölçeğin İngilizce formundan elde edilen puanlarla Türkçe formundan elde edilen puanlar arasındaki korelasyona bakılmıştır. 
Korelasyon analizi sonucuna göre, ölçeğin İngilizce ve Türkçe formu arasında pozitif yönde, yüksek düzeyde ve anlamlı bir ilişki vardır $(\mathrm{r}=.83 ; \mathrm{p}<.05)$. Bu sonuç ölçeğin İngilizce ve Türkçe formunun eş değer olduğu anlamına gelmektedir (Seçer, 2015).

\section{Pilot Uygulama}

Ölçeğin dilsel geçerliğinin incelenmesinden sonra geçerlik ve güvenirlik çalışmalarına geçilmeden önce pilot uygulama yapılarak ölçeğin her bir maddesine ilişkin madde toplam korelasyon katsayısı ve ölçeğin geneli için Cronbach Alfa değeri incelenmiştir. Seçer (2015) pilot uygulamanın yapılacağı kişi sayısının belirlenmesinde ölçekteki madde sayısının belirleyici olduğunu ifade etmektedir. Madde sayısı 30 kadar olan ölçeklerde en az 50 kişiye uygulanması gerektiğini belirtmektedir. $\mathrm{Bu}$ kapsamda Kilis 7 Aralık Üniversite-Muallim Rifat Eğitim Fakültesinde öğrenim gören 60 öğrenciye ölçeğin Türkçe formu uygulanmıştır. Ölçeğe ait madde toplam korelasyon değerleri tablo 1'de grüldüğü gibidir.

Tablo 1: Madde Toplam Korelasyon Değerleri

\begin{tabular}{cccc}
\hline Maddeler & Madde toplam korelâsyonu & Maddeler & Madde toplam korelâsyonu \\
\hline SG1 & .558 & SG10 & .452 \\
SG2 & .404 & SG11 & .286 \\
SG3 & .542 & SG12 & .560 \\
SG4 & .176 & SG13 & .457 \\
SG5 & .400 & SG14 & .467 \\
SG6 & .379 & SG15 & .407 \\
SG7 & .571 & SG16 & .399 \\
SG8 & .484 & SG17 & .262 \\
SG9 & .429 & SG18 & .575 \\
\hline
\end{tabular}

Tablo 1'de ölçeği oluşturan her bir maddeye ilişkin madde toplam korelasyon değerleri incelendiğinde 4. maddeye ait değerin .176, diğer maddelerin ise .262 ile .571 arasında değiştiği görülmektedir. Madde toplam korelasyon değerinin en az .20 ya da .25 olması gerektiği ifade edilmektedir (Tavşancıl, 2002). Bu bağlamda 4. maddenin toplam korelasyon katsayısının .20'nin altında kalması, maddenin ölçeğin geneli ile uyumlu olmadığı anlamına gelmektedir. Bu nedenle 4. maddenin ölçekten çıkarılmasına karar verilmiştir. Dördüncü maddenin çıkarılması ile ölçekte 17 madde kalmıştır. Ölçeğin geneli için Cronbach Alfa değeri .83 olarak hesaplanmıştır. Cronbach Alfa değerinin .70 üzeri olmas1 ölçeğin iç tutarlılığa sahip olduğu şeklinde değerlendirilmiştir (Büyüköztürk, 2012; Seçer, 2015).

\section{Yapı Geçerliğinin İncelenmesi}

Alan yazında, ölçek uyarlama çalışmalarında açımlayıcı faktör analizi yerine ölçeğin mevcut yapısını doğrulamaya yönelik doğrulayıcı faktör analizi yapılması gerektiği vurgulanmaktadır (Seçer, 2015). Yapı geçerliğinin doğrulamak amacıyla ise en az 300 katılımcıya ölçeğin uygulanması gerektiği belirtilmektedir (Çokluk, Şekercioğlu ve Büyüköztürk, 2012; Seçer, 2015). Bu amaçla Kilis 7 Aralık Üniversitesinin farklı fakülte ve yüksek okullarından araştırmaya gönüllü olarak katılan 305 öğrenciye ölçek uygulanmıştır. 305 öğrenciden toplanan veriler kullanılarak doğrulayıcı faktör analizi yapılmıştır. Doğrulayıcı aktör analizi farklı kültürlerde ve örneklemlerde geliştirilmiş olan ölçeklerin uyarlanmasında kullanılan bir geçerlilik belirleme yöntemidir (Meydan ve Şeşen, 2015; Seçer, 2015). Sosyal girişimcilik öncülleri ölçeğinin DFA sonuçları şekil 1'de görüldüğü gibidir. 


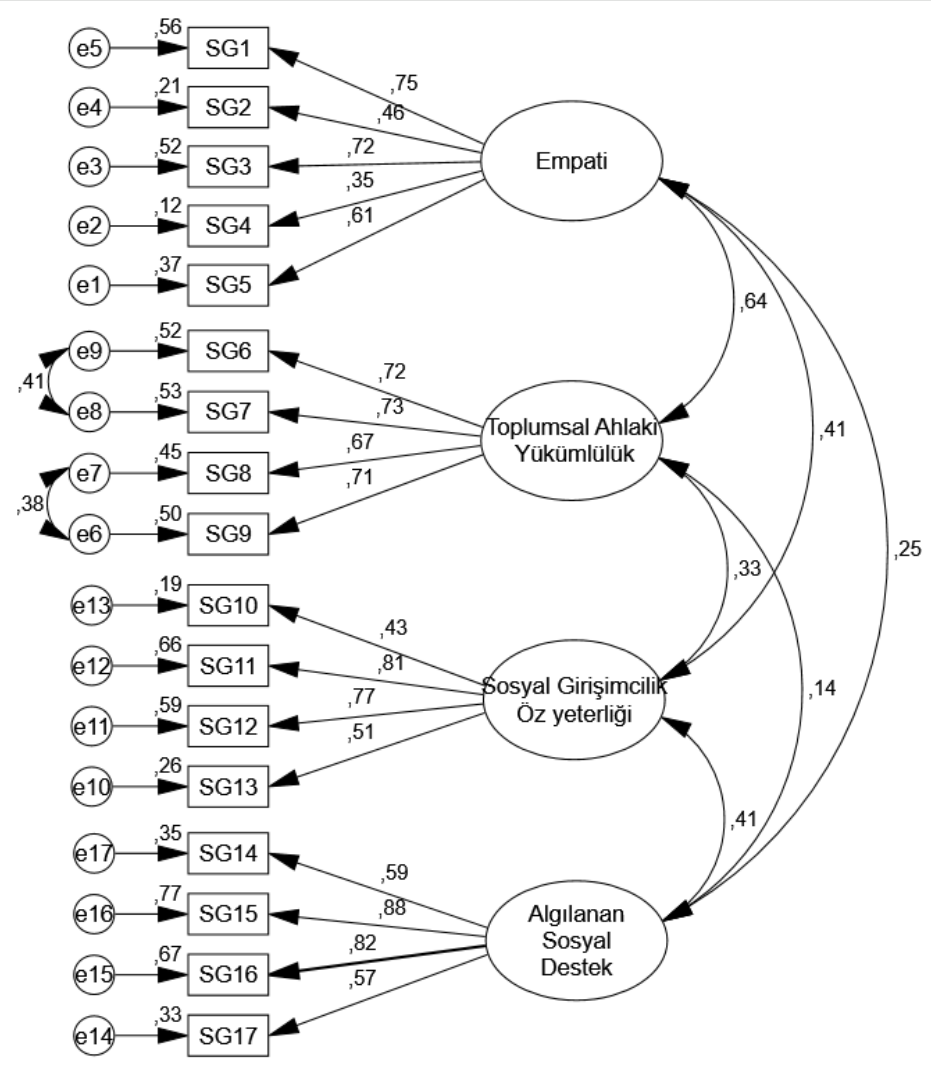

Şekil 1: Sosyal Grişimcilik Öncülleri Ölçeğinin DFA sonuçları

Şekil 1'de 17 madde ve 4 faktörden oluşan sosyal girişimcilik öncülleri ölçeğinin doğrulayıcı faktör analizi model uyumu değerlerinin kabul edilebilir düzeyde olduğu görülmektedir $\left(\chi^{2} / \mathrm{Sd}=248.29 / 111=2.34 ; \mathrm{p}<.05, \mathrm{CFI}=.92 ; \mathrm{TLI}=.91 ; \mathrm{GFI}=.91 ; \mathrm{SRMR}=.076 ; \mathrm{RMSEA}=\right.$ .064). Ölçeğin alt boyutlarına ilişkin faktör yükleri şekil l'de görüldügü gibidir. Faktör yükleri; empati boyutunda .35 ile .75 arasında, ahlaki yükümlülük boyutunda .67 ile.73 arasında, öz yeterlik alt boyutunda .43 ile .81 arasında, sosyal destek alt boyutunda .57 ile .88 arasında değişmektedir. Faktör yükü, maddelerinin ölçek faktörleri ile ilişkisini açıklayan bir değerdir. Herhangi bir maddenin faktör yükünün düşük olması, söz konusu maddenin ait olduğu faktörle yeterince güçlü bir ilişkisinin olmadığı anlamına gelmektedir (Kline, 1994). Alan yazında faktör yükünün en az .30 olması gerektiği ile ilgili genel bir kabul vardır (Büyüköztürk, 2012; Seçer, 2015). Bu çalışmada da faktör yükleri ile ilgili bu görüş temel alınmıştır.

\section{Güvenirlik Çalışması}

Sosyal girişimcilik öncülleri ölçeğinin güvenirliği; test-tekrar test ve iç tutarlılık güvenirliği yöntemleri ile incelenmiş̧ir. Test-tekrar test güvenirlik analizi 95 ögrenci ile gerçekleştirilmiştir. Bu sayının belirlenmesinde madde sayısının en az 5 katı olması kuralı esas alınmıştır (MacCallum, Widaman, Zhang ve Hong, 1999; Erkuş, 2012). Ölçeğin Türkçe formu 3 hafta arayla araştırma grubuna uygulanmış ve iki uygulama arasındaki ilişki, korelasyon analizi ile incelenmiştir. Cronbach Alfa değerleri ve test-tekrar test sonuçları tablo 2'de görüldüğü gibidir.. 
Tablo 2: Sosyal Girişimcilik Öncülleri Ölçeğine Ait Cranbach Alfa ve Test-Tekrar Test Sonuçları

\begin{tabular}{lcc}
\hline Boyutlar & Cronbach Alfa & Test-Tekrar Test \\
\hline Empati & .70 & .80 \\
Toplumsal Ahlaki Yükümlülük & .83 & .79 \\
Sosyal Girişimcilik Öz yeterliği & .72 & .71 \\
Algilanan Sosyal Destek & .81 & .88 \\
Ölçeğin Geneli & .82 & .81 \\
\hline
\end{tabular}

Tablo 2 incelendiğinde ölçeğin geneli ve alt boyutlarına ilişkin Cronbach Alfa iç tutarlık katsayısının .70 ve üzeri olduğu görülmektedir. Test-tekrar test sonuçları incelendiğinde ise ölçeğin geneli ve alt boyutlarına ilişkin iki uygulama arasındaki korelasyon katsayısının .71 ve üzerinde olduğu dikkat çekmektedir. Hem Cronbach Alfa katsayısının hem de iki uygulama arasındaki korelasyon katsayısının .70 ve üzeri olması ölçeğin iç tutarlığa sahip olduğunu ve uygulamadan uygulamaya tutarlı sonuçlar verdiği anlamına gelmektedir (Büyüköztürk, 2012; Seçer, 2015). Bu kapsamda ölçeğin güvenilir olduğu söylenebilir.

\section{Sonuç}

$\mathrm{Bu}$ araştırmanın amacı, Mair ve Noboa (2006) tarafından ortaya konulmuş olan ve sosyal girişimcilik niyetinin oluşumunu açıklayan modele dayalı olarak, Hockerts (2015) tarafindan geliştirilmiş olan, sosyal girişimcilik öncülleri ölçeğini Türkçeye uyarlamaktır. Bu amaçla 18 madde ve 4 faktörden (empati, ahlaki yükümlülük, sosyal girişimcilik öz yeterliği ve algılanan sosyal destek) oluşan ölçeğin Türkçeye uyarlanması kapsamında geçerlik ve güvenirlik analizleri yapılmıştır.

Ölçeğin Türkçeye uyarlanması ile ilgili gerekli izinlerin alınmasının ardından öncelikle ölçek alan yazında belirtilen ilkelere uygun olarak (Brislin, Lonner ve Thorndike, 1973; Savaşır, 1994) Türkçeye çevrilmiş ve ölçeğin İngilizce formu ile Türkçe formunun eş değer olup/olmadığ test edilmiştir. Yapılan analizler sonucunda ölçeğin İngilizce ve Türkçe formu arasındaki ilişkinin .83 olduğu görülmüştür. Bu bulgudan, ölçeğin Türkçe formunun İngilizce formu ile dilsel olarak eş değer olduğu sonucu çıkartılmıştır (Seçer, 2015).

Dilsel eşdeğerlik çalışmasının ardından Seçer'in (2015) önerdiği gibi ölçeğin Türkçe formu ile pilot uygulama yapılmış ve ölçeğin geneline ilişkin Cronbach Alfa katsayısı ve ölçeğin her bir maddesine ilişkin madde toplam korelasyon değerleri hesaplanmıştır. Analiz sonucunda yapılan incelemelerde 4. maddeye ait madde toplam korelasyon değerinin .20'nin altında olduğu görülmüştür. Bu nedenle ilgili maddenin ölçekten çıkarılmasına karar verilmiştir (Büyüköztürk, 2002; Seçer, 2015; Tavşancıl, 2002). 4. madde ölçekten çıkartıldıktan sonra geriye 17 madde kalmıştır. Geriye kalan maddelerin birbirleriyle ve ölçeğin geneli ile uyumlu olduğu ve her bir maddenin ölçeğin özelliğini ayırt etme gücüne sahip olduğu sonucuna ulaşılmıştır (Büyüköztürk, 2012; Seçer, 2015). 17 madde ve 4 alt boyuttan oluşan ölçeğin mevcut yapısının geçerliğini test etmek amacıyla DFA yapılmışıı. DFA sonucunda ölçeğin mevcut yapısının model uyumuna sahip olduğu görülmüştür. Ölçeği oluşturan maddelerin faktör yüklerinin .35 ile .88 arasında değiştiği belirlenmiştir. $\mathrm{Bu}$ bulguya dayalı olarak her bir ölçek maddesinin ilgili boyutla ilişkili olduğu sonucuna varılmıştır (Büyüköztürk, 2012; Seçer, 2015).

Geçerlik çalışmalarından sonra ölçeğin güvenirliği test edilmiştir. Güvenirliğin test edilmesinde Cronbach Alfa iç tutarlılık ve test-tekrar test analiz sonuçları kullanılmıştır. Elde edilen bulgulara dayalı olarak ölçeğin iç tutarlılığa sahip olduğu ve uygulamadan uygulamaya tutarl1 sonuçlar verdiği sonucuna ulaşılmıştır (Büyüköztürk, 2012; Seçer, 2015). Geçerlik ve güvenirlik analiz sonuçlarına dayalı olarak "Sosyal Girişimcilik Öncülleri Ölçeğinin" Türkçe formunun geçerli ve güvenilir olduğu söylenebilir.

Hockerts (2015) tarafindan geliştirilmiş olan “Sosyal Girişimcilik Öncülleri Ölçeği”nin Türkçe uyarlaması, 17 madde ve 4 alt boyuttan oluşmaktadır. Ölçeğin alt boyutları empati (1., 2., 
3., 4., 5. maddeler), toplumsal ahlaki yükümlülük (6., 7., 8., ve 9. maddeler), sosyal girişimcilik öz yeterliği (10., 11., 12. ve 13. maddeler) ve algilanan sosyal destektir (14., 15., 16. ve 17. maddeler). Ölçekte yer alan 2., 5., 13. ve 17. maddeler olumsuz yargı bildirdiği için ters puanlanmaktadır. Ölçek 5'li likert puanlamaya sahiptir $(1=$ Kesinlikle katılmıyorum...5= Kesinlikle katılıyorum). Ölçeğin alt boyutlarının yanı sıra ölçeğin genel puanı da hesaplanabilir. Bu ölçekle katılımcıların; sosyal girişimcilik niyetleri, sosyal girişimcilik eğilimleri ve sosyal girişimcilik özelliklerinin incelenmesi mümkündür. Bu ölçek özellikle sosyal girişimcilik eğitiminin verildiği kurumlarda, katılımcıların mevcut durumunu ortaya koymada yetkililere yardımcı olabilir.

\section{Kaynakça}

Akar, H. \& Aydın, S. (2015). Öğretmen adaylarinin kişilik özelliklerinin sosyal girişimcilik özelliklerini yordama düzeyi. The Journal Of Academic Social Science,3(12), 425-436. http://dx.doi.org/10.16992/ASOS.647

Akar, H., \& Dogan, Y. B. (2018). The role of personal values in social entrepreneurship. Universal Journal of Educational Research, 6(1), 83-90. http://dx.doi.org/10.13189/ujer.2018.060107

Akar, H., \& Üstüner, M. (2017). Mediation role of self-efficacy perceptions in the relationship between emotional intelligence levels and social entrepreneurship traits of pre-service teachers. Journal of Education and Future, (12), 95-115.

Alvord, S. H., Brown, L. D., \& Letts, C. W. (2004). Social entrepreneurship and societal transformation: An exploratory study. The Journal of Applied Behavioral Science, 40(3), 260-282. https://doi.org/10.1177/0021886304266847

Anheier, H., \& Themudo, N. (2002). Organisational forms of global civil society: implications of going global. Global Civil Society, 2(1), 42-47.

Austin, J., Stevenson, H., \& Wei-Skillern, J. (2006). Social and commercial entrepreneurship: Same, different, or both? Entrepreneurship Theory and Practice, 30(1), 1-22. https://doi.org/10.1111/j.1540-6520.2006.00107.x

Aydogmus, M. (2019). Investigation of the effect of social entrepreneurship on professional attitude and self-efficacy perception: a research on prospective teachers. Studies in Higher Education, 1-15. https://doi.org/10.1080/03075079.2019.1673719

Ayob, N., Yap, C. S., Sapuan, D. A., \& Rashidd, Z. A. (2013). Social entrepreneurial intention among business undergraduates: an emerging economy perspective. Gadjah Mada International Journal of Business, 15(3). https://doi.org/10.22146/gamaijb.5453

Beck, L., \& Ajzen, I. (1991). Predicting dishonest actions using the theory of planned behavior. Journal of Research in Personality, 25(3), 285-301. https://doi.org/10.1016/00926566(91)90021-H

Bornstein, D. (1998). Changing the world on a shoestring. Atlantic Monthly, 281(1), 34-38.

Borzaga, C. \& Depedri, S. (2013). When social enterprises do it better: efficiency and efficacy of work integration in Italian social cooperatives, in S. Denny \& F. Simmon (Eds.) Social Enterprises. Accountability and Evaluation around the World. London: Routledge, pp. 85101.

Boyd, N. G., \& Vozikis, G. S. (1994). The influence of self-efficacy on the development of entrepreneurial intentions and actions. Entrepreneurship Theory and Practice, 18(4), 6377. https://doi.org/10.1177/104225879401800404 
Brislin, R.W., Lonner, W. J. \& Thorndike, R. M. (1973). Cross cultural research method. New York: John Wiley and Sons.

Büyüköztürk, Ş. (2012). Sosyal bilimler için veri analiz el kitabı. Ankara: Pegem Akedemi Yayınc1lik. https://doi.org/10.14527/9789756802748

Çokluk, Ö., Şekercioğlu, G. \& Büyüköztürk, Ş. (2012). Sosyal bilimler için çok değişkenli istatistik SPSS ve LISREL uygulamalarl. (2.Bask1). Ankara: Pegem Akademi Yayınc1l1k. https://doi.org/10.14527/9789756802335

Decety, J. \& Jackson, P. L. (2004). The functional architecture of human empathy. Behavioral and Cognitive Neuroscience Reviews, 3(2), 71-100. https://doi.org/10.1177/1534582304267187

Dees, J. G. (2001). The meaning of "social entrepreneurship". Comments and suggestions contributed from the Social Entrepreneurship Founders Working Group. Durham: Center for the Advancement of Social Entrepreneurship, Fuqua School of Business, Duke University. Erişim: http://www.caseatduke.org/documents /dees_sedef.pdf https://doi.org/10.4324/9781351278560-5

Dees, J. G. (2012). A tale of two cultures: Charity, problem solving, and the future of social entrepreneurship. Journal of Business Ethics, 111(3), 321-334. https://doi.org/10.1007/s10551-012-1412-5

Dökmen, Ü. (2013). Illetişim çatışmaları ve empati. Istanbul, Türkiye: Remzi Yayınevi.

Drayton, W. (2002). The citizen sector: Becoming as entrepreneurial and competitive as business. California Management Review, 44(3), 120-132. https://doi.org/10.2307/41166136

Eisenberg, N., \& Miller, P. A. (1987). The relation of empathy to prosocial and related behaviors. Psychological Bulletin, 101(1), 91-119. https://doi.org/10.1037/0033-2909.101.1.91

Erkuş, A. (2012). Psikolojide ölçme ve ölçek gelişstirme. Ankara: Pegem Akademi Yayınları. https://doi.org/10.14527/9786052416594

Fitzsimmons, J. R., \& Douglas, E. J. (2011). Interaction between feasibility and desirability in the formation of entrepreneurial intentions. Journal of Business Venturing, 26(4), 431-440. https://doi.org/10.1016/j.jbusvent.2010.01.001

Forster, F., \& Grichnik, D. (2013). Social entrepreneurial intention formation of corporate volunteers. Journal of Social Entrepreneurship, 4(2), 153-181. https://doi.org/10.1080/19420676.2013.777358

Haugh, H. (2007). Community-led social venture creation. Entrepreneurship theory and practice, 31(2), 161-182. https://doi.org/10.1111/j.1540-6520.2007.00168.x

Henton, D., Melville, J., \& Walesh, K. (1997). The age of the civic entrepreneur: restoring civil society and building economic community. National Civic Review, 86(2), 149-156. https://doi.org/10.1002/ncr.4100860208

Hockerts, K. (2010). Social entrepreneurship between market and mission. International Review of Entrepreneurship, 8 (2), 177-198.

Hockerts, K. (2015). The social entrepreneurial antecedents scale (SEAS): A validation study. Social Enterprise Journal, 11(3), 260-280. https://doi.org/10.1108/SEJ-05-2014-0026

Hockerts, K. (2017). Determinants of social entrepreneurial intentions. Entrepreneurship Theory and Practice, 41(1), 105-130. https://doi.org/10.1111/etap.12171

Ip, C. Y., Liang, C., Wu, S. C., Law, K. M. Y., \& Liu, H. C. (2018). Enhancing social entrepreneurial intentions through entrepreneurial creativity: A comparative study between 
Taiwan and Hong Kong. Creativity Research Journal, 30(2), 132-142. https://doi.org/10.1080/10400419.2018.1446744

Ip, C. Y., Wu, S. C., Liu, H. C., \& Liang, C. (2017). Revisiting the antecedents of social entrepreneurial intentions in Hong Kong. International Journal of Educational Psychology, 6(3), 301-323. http://dx.doi.org/10.17583/ijep.2017.2835

Konakl1, T. (2015). Effects of self-efficacy on social entrepreneurship in education: a correlational research. Research in Education, 94(1), 30-43. https://doi.org/10.7227/RIE.0019

Konaklı, T., \& Göğüş, N. (2013). Aday öğretmenlerin sosyal girişimcilik özellikleri ölçeği: geçerlik ve güvenirlik çalışması. Gazi University Journal of Gazi Educational Faculty (GUJGEF), 33(2).

Kümbül Güler, B. (2008). Sosyal girişimciliği etkileyen faktörlerin analizi, Yayımlanmamış doktora tezi, Dokuz Eylül Üniversitesi Sosyal Bilimleri Enstitüsü, İzmir.

MacCallum, R. C., Widaman, K. F., Zhang, S., \& Hong, S. (1999). Sample size in factor analysis. Psychological Methods, 4(1), 84-99. https://doi.org/10.1037/1082-989X.4.1.84

Mair, J., \& Marti, I. (2006). Social entrepreneurship research: A source of explanation, prediction, and delight. Journal of world business, 41(1), 36-44. https://doi.org/10.1016/j.jwb.2005.09.002

Mair, J., \& Noboa, E. (2006). Social entrepreneurship: How intentions to create a social venture are formed. In Social entrepreneurship (pp. 121-135). Palgrave Macmillan, London. https://doi.org/10.1057/9780230625655_8

McDonald, N. M., \& Messinger, D. S. (2010). The Development of Empathy: How, When, and Why. Department of Psychology, University of Miami: USA

Meydan, C.H. \& Şeşen H. (2015). Yapısal Eşitlik Modellemesi AMOS Uygulamaları. Ankara: Detay Yayınc1lik.

Miller, T. L., Grimes, M. G., McMullen, J. S., \& Vogus, T. J. (2012). Venturing for others with heart and head: How compassion encourages social entrepreneurship. Academy of Management Review, 37(4), 616-640. https://doi.org/10.5465/amr.2010.0456

Nga, J. K. H., \& Shamuganathan, G. (2010). The influence of personality traits and demographic factors on social entrepreneurship start up intentions. Journal of Business Ethics, 95(2), 259-282. https://doi.org/10.1007/s10551-009-0358-8

Pearce, J. (2003). Social Enterprise in Anytown, Calouste Gulbenkian Foundation, London.

Prabhu, G. N. (1999). Social entrepreneurial leadership. Career Development International, 4(3), 140-145. https://doi.org/10.1108/13620439910262796

Sassmannshausen, S. P., \& Volkmann, C. (2013). A bibliometric based review on social entrepreneurship and its establishment as a field of research (No. 2013-003). Schumpeter Discussion Papers.

Savaşır, I. (1994). Ölçek uyarlamasındaki bazı sorunlar ve çözüm yolları. Türk Psikoloji Dergisi, 33 (9), 27-32.

Seçer, İ. (2015). Psikolojik test geliştirme ve uyarlama süreci: SPSS ve LISREL uygulamalart. Ankara: Anı Yayıncılık.

Sezen-Gultekin, G., \& Gur-Erdogan, D. (2016). The relationship and effect between lifelong learning tendencies and social entrepreneurship characteristics of prospective teachers. The Anthropologist, 24(1), 113-118. https://doi.org/10.1080/09720073.2016.11891996 
Shaw, E., \& Carter, S. (2007). Social entrepreneurship: Theoretical antecedents and empirical analysis of entrepreneurial processes and outcomes. Journal of Small Business and Enterprise Development, 14(3), 418-434. https://doi.org/10.1108/14626000710773529

Sivathanu, B., \& Bhise, P. V. (2013). Challenges for social entrepreneurship. International Journal of Application or Innovation in Engineering \& Management, (Special Issue), 1-9.

Snellman, L.(2016). Social entrepreneurship: making change in the world? Journal of Logistics, Informatics and Service Science, 3(1), 1-25

Tavşancıl, E. (2002). Tutumların ölçülmesi ve SPSS ile veri analizi. Nobel Yayıncılık, Ankara.

Taylor, D. W., \& Thorpe, R. (2004). Entrepreneurial learning: a process of co-participation. Journal of Small Business and Enterprise Development, 11(2), 203-211. https://doi.org/10.1108/14626000410537146

Teise, H., \& Urban, B. (2015). Antecedents to social entrepreneurship intentions: An empirical study in South Africa. Management Dynamics: Journal of the Southern African Institute for Management Scientists, 24(2), 36-52.

Thake, S., \& Zadek, S. (1997). Practical people, noble causes: How to support community-based social entrepreneurs. Executive Summary. New Economics Foundation.

Tiwari, P., Bhat, A. K., \& Tikoria, J. (2017). An empirical analysis of the factors affecting social entrepreneurial intentions. Journal of Global Entrepreneurship Research, 7(1), 9. https://doi.org/10.1186/s40497-017-0067-1

Tyszka, T., Cieślik, J., Domurat, A., \& Macko, A. (2011). Motivation, self-efficacy, and risk attitudes among entrepreneurs during transition to a market economy. The Journal of Socio-Economics, 40(2), 124-131. https://doi.org/10.1016/j.socec.2011.01.011

Yazıc1, K., Uslu, S., \& Arık, S. (2016). The investigation of the social entrepreneurship characteristics of social studies pre-service teachers. Cogent Education, 3(1), 1141455. https://doi.org/10.1080/2331186X.2016.1141455

Zahra, S. A., Gedajlovic, E., Neubaum, D. O., \& Shulman, J. M. (2009). A typology of social entrepreneurs: Motives, search processes and ethical challenges. Journal of Business Venturing, 24(5), 519-532. https://doi.org/10.1016/j.jbusvent.2008.04.007

Chinchilla, A., \& Garcia, M. (2017). Social entrepreneurship intention: Mindfulness towards a duality of objectives. Humanistic Management Journal, 1(2), 205-214. https://doi.org/10.1007/s41463-016-0013-3 


\section{EK 1: Sosyal Girişimcilik Öncülleri Ölçeği}

\begin{tabular}{|c|c|c|c|c|c|c|}
\hline & & 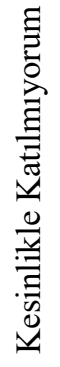 & 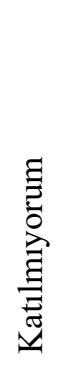 & 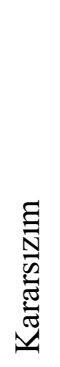 & 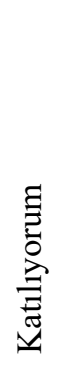 & 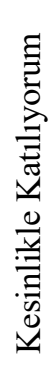 \\
\hline \multicolumn{7}{|c|}{ Empati } \\
\hline 1 & $\begin{array}{l}\text { Toplumda, dezavantajlı durumdaki insanları düşündüğümde, kendimi } \\
\text { onların yerine koymaya çalışırım. }\end{array}$ & 1 & 2 & 3 & 4 & 5 \\
\hline 2 & $\begin{array}{l}\text { Toplumda, dezavantajlı koşullarda yaşayan insanların ne hissettiğini } \\
\text { umursamam. }\end{array}$ & 1 & 2 & 3 & 4 & 5 \\
\hline 3 & $\begin{array}{l}\text { Toplumda, dezavantajlı durumdaki insanları görmek, beni duygusal } \\
\text { olarak etkiler. }\end{array}$ & 1 & 2 & 3 & 4 & 5 \\
\hline 4 & Toplumda, kenara itilmiş/dışlanmış insanlara merhamet duyarım. & 1 & 2 & 3 & 4 & 5 \\
\hline 5 & Benden daha az şanslı insanlara merhamet duymakta zorlanırım. & 1 & 2 & 3 & 4 & 5 \\
\hline \multicolumn{7}{|c|}{ Toplumsal Ahlaki Yükümlülük } \\
\hline 6 & Bizden daha az şanslı insanlara yardım etmek etik bir sorumluluktur. & 1 & 2 & 3 & 4 & 5 \\
\hline 7 & $\begin{array}{l}\text { Toplumda, dezavantajlı durumdaki insanlara yardım etmek bizim için } \\
\text { ahlaki bir yükümlülüktür. }\end{array}$ & 1 & 2 & 3 & 4 & 5 \\
\hline 8 & Sosyal adalet, bizden daha az şanslı insanlara yardım etmemizi gerektirir. & 1 & 2 & 3 & 4 & 5 \\
\hline 9 & $\begin{array}{l}\text { Dezavantajlı durumdaki insanlara yardım etme gerekliliği, toplumsal } \\
\text { ilkelerdendir. }\end{array}$ & 1 & 2 & 3 & 4 & 5 \\
\hline \multicolumn{7}{|c|}{ Sosyal Girişimcilik Öz Yeterliği } \\
\hline 10 & $\begin{array}{l}\text { Toplumsal problemleri çözmek, hepimizin katkıda bulunabileceği bir } \\
\text { şeydir. }\end{array}$ & 1 & 2 & 3 & 4 & 5 \\
\hline 11 & $\begin{array}{l}\text { Kafama koyarsam, toplumsal sorunların çözümüne katkıda } \\
\text { bulunabileceğime inanıyorum. }\end{array}$ & 1 & 2 & 3 & 4 & 5 \\
\hline 12 & $\begin{array}{l}\text { Toplumun karşılaştığı problemleri çözmeye yardım edecek bir yol } \\
\text { bulabilirim. }\end{array}$ & 1 & 2 & 3 & 4 & 5 \\
\hline 13 & Önemli bir toplumsal değişime yol açabileceğime inanmıyorum. & 1 & 2 & 3 & 4 & 5 \\
\hline \multicolumn{7}{|c|}{ Algılanan Sosyal Destek } \\
\hline 14 & $\begin{array}{l}\text { Toplumsal sorunları çözmek isteyen bir örgüt/kurum için } \\
\text { yatırımcıları/destekçileri çekmek mümkündür. }\end{array}$ & 1 & 2 & 3 & 4 & 5 \\
\hline 15 & $\begin{array}{l}\text { Toplumda, kenara itilmiş̧/dışlanmış insanlara yardım etmek için bir } \\
\text { örgüt(dernek, vakıf vb.) kurmak isteseydim insanlar bana destek olurdu. }\end{array}$ & 1 & 2 & 3 & 4 & 5 \\
\hline 16 & $\begin{array}{l}\text { Ĕger önemli bir toplumsal sorunu çözmeyi planlasaydım, insanlar beni } \\
\text { desteklerdi. }\end{array}$ & 1 & 2 & 3 & 4 & 5 \\
\hline 17 & $\begin{array}{l}\text { Sosyal bir girişim (dernek, vakıf vb.) kursaydım çok fazla } \\
\text { destekleneceğimi düșünmüyorum. }\end{array}$ & 1 & 2 & 3 & 4 & 5 \\
\hline
\end{tabular}

